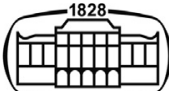

AKADÉMIAI KIADÓ

Acta Chromatographica

34 (2022) 2, 179-184

DOl:

$10.1556 / 1326.2021 .00854$

(c) 2021 The Author(s)

\section{ORIGINAL RESEARCH}

PAPER

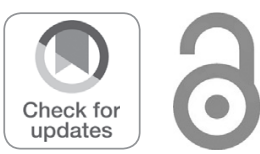

\title{
Development of a rapid LC-MS/MS assay to determine letrozole in human plasma and its application in a pharmacokinetic study after oral administration
}

\author{
PENGFEI LI ${ }^{1}$, XI ZHANG ${ }^{1}$, SHUMIN WANG ${ }^{1}$, JING WANG ${ }^{2}$, \\ ZIQI LIU ${ }^{2}$, CHEN WANG ${ }^{2}$, WEIHANG TONG ${ }^{2 *}$ (i) and \\ LIHONG LIU ${ }^{1 *}$ (])
}

\author{
${ }^{1}$ Pharmacy Department of Beijing Chao-yang Hospital, Capital Medical University, No.8 Gongti \\ South Road, Chaoyang District, Beijing 10020, China \\ ${ }^{2}$ Pharmacy Department of the Rocket General Hospital PLA, No.16 Xinwai Road, Xicheng District, \\ Beijing 100088, China
}

Received: September 10, 2020 • Accepted: April 17, 2021

Published online: June 1, 2021

\begin{abstract}
Letrozole is one of the third generation aromatase inhibitors. It is suitable for the treatment of postmenopausal patients with advanced breast cancer and early treatment of breast cancer. It is necessary to develop a rapid, reliable, selective and sensitive LC-MS/MS assay to determine letrozole in human plasma to evaluate the clinical efficacy and adverse reactions with clinical pharmacokinetic and therapeutic drug monitoring. Separation was carried out on a Kromasil- $\mathrm{C}_{18}$ column using acetonitrile-water $(55: 45, \mathrm{v} / \mathrm{v})$ as mobile phase. Detection was carried out by multiple reaction monitoring on a 3200Qtrap mass spectrometry. The method needed one-step protein precipitation procedure only, and the cycle time was $2.5 \mathrm{~min}$ allowing $500-550$ samples per day. It was linear within $0.30-50.00 \mathrm{ng} / \mathrm{mL}$ for plasma with the limit of detection (LOD) of $0.030 \mathrm{ng} / \mathrm{mL}$. The intra- and inter-day RSD were 5.51-8.63\%, 2.28$9.95 \%$ and the RE was $0.18-1.65 \%$. The recovery rates of letrozole and internal standard for plasma were 89.30-98.55\%. Letrozole was stable under all the conditions in the study. The method was sensitive enough to quantitate letrozole over a period of $288 \mathrm{~h}$ after giving a single oral dose of $2.5 \mathrm{mg}-24$ Chinese healthy volunteers. The absorption of letrozole was rapid with small individual difference, the tissue distribution of letrozole was more than that in blood, and the clearance was slow. Letrozole was similar to three-compartment model in vivo. Due to metabolism and excretion, the AUCs of letrozole varied greatly among individuals.
\end{abstract}

\section{KEYWORDS}

letrozole, LC-MS/MS, LC-ESI-Qtrap, pharmacokinetics, protein precipitation

\section{INTRODUCTION}

Letrozole is one of the third generation aromatase inhibitors. It can effectively inhibit the conversion of androgen to estrogen. Because of its high selectivity, it does not affect glucocorticoid and thyroid function, and high-dose use has no inhibitory effect on the secretion of adrenal corticosteroids, so it has a high therapeutic index $[1,2]$. It is suitable for the treatment of postmenopausal patients with advanced breast cancer and early treatment of breast cancer. Importantly, letrozole is indicated for the extended adjuvant treatment of early breast cancer in postmenopausal women, who have received 5 years of adjuvant tamoxifen therapy [3]. In this extended adjuvant setting, letrozole reduces the risk of breast cancer recurrence by $42 \%$, irrespective of nodal status and prior chemotherapy [4].

${ }^{*}$ Corresponding authors. E-mail: sonatawh@163.com; liulihong@bjcyh.com 
Letrozole is rapidly and completely absorbed from the gastrointestinal tract and absorption is not affected by food [5]. Letrozole's terminal elimination half-life is about 2 days and steady-state plasma concentration after daily $2.5 \mathrm{mg}$ dosing is reached in 2-6 weeks [6]. Letrozole is weakly protein bound and has a large volume of distribution. Almost all the metabolites and about 5\% of the original drug are excreted through the kidney [7].

HPLC-UV [8, 9], HPLC-FL [10], Micellar electrokinetic chromatography $[11,12]$ and LC-MS/MS [13-16] method has been developed for determination of letrozole in plasma and urine. However, these methods suffer from disadvantages such as low sensitivity $(10 \mathrm{ng} / \mathrm{mL})$, time-consuming sample preparation and larger bio-samples. It is necessary to develop a rapid, reliable, selective and sensitive LC-MS/MS assay to determine letrozole in human plasma to evaluate the clinical efficacy and adverse reactions with clinical pharmacokinetic and therapeutic drug monitoring. In the present work, we described a LC-MS/MS method for the determination of letrozole in human plasma after one-step protein precipitation with the lower limit of quantitation (LLOQ) 0.3 $\mathrm{ng} / \mathrm{mL}$ using a common LC-MS/MS analysis platform. The full validation included calculation curve, selectivity, accuracy, precision, stability, matrix effect and recovery. The proposed method was successfully applied to a clinical pharmacokinetic study in Chinese healthy volunteers.

\section{EXPERIMENTAL}

\section{Reagents and reagents}

Letrozole (99.7\%) (Fig. 1A) was purchased from U.S. Pharmacopeia and omeprazole (99.0\%) (Fig. 1B) used as internal standard was purchased from the National Institute for the Control of Pharmaceutical and Biological Products (Beijing, China). Acetonitrile was HPLC grade and purchased from Fisher Scientific (Fair Lawn, NJ, USA). Blank (drug free) human plasma was obtained from the Rocket General Hospital PLA (Beijing, China). Distilled, demineralized water was produced by a Milli-Q Reagent Water System (Millipore, MA, USA).

\section{LC-MS/MS instrumentations and conditions}

The LC-MS/MS system consisted of an Agilent 1100 series HPLC (Agilent Technologies, Palo Alto, CA, USA) coupled to an Applied Biosystems Sciex 3200Qtrap ${ }^{\text {TM }}$ mass spectrometer (Applied Biosystems Sciex, Ontario, Canada).

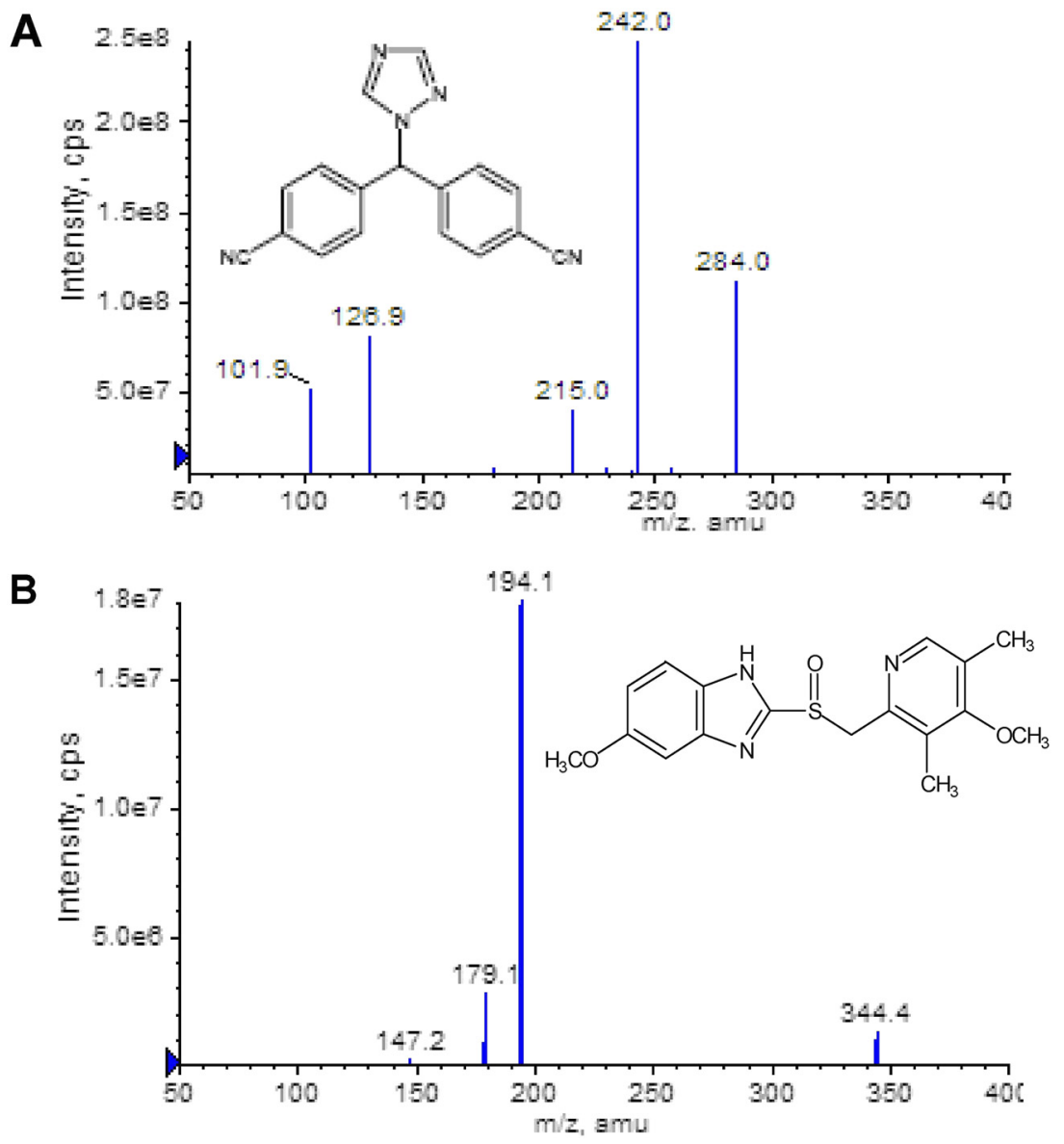

Fig. 1. Full-scan product ion spectra of $[\mathrm{M}-\mathrm{H}]^{-}$for (A) letrozole and (B) omeprazole 
Applied Biosystems/MDS SCIEX Analyst 1.5.1 software was used for data acquisition and processing.

Chromatography was carried out on a $50 \mathrm{~mm} \times 4.6$ $\mathrm{mm}, 5 \mu \mathrm{m}$ Kromasil- $\mathrm{C}_{18}$ column maintained the temperature at $30{ }^{\circ} \mathrm{C}$. Acetonitrile-water $(55: 45, \mathrm{v} / \mathrm{v})$ was used as mobile phase with a flow-rate of $1.0 \mathrm{~mL} / \mathrm{min}$. The column effluent was split so that approximately $0.5 \mathrm{~mL} / \mathrm{min}$ entered the mass spectrometer.

The electrospray ion (ESI) source was used in negative ion mode for all experiments. The LC-MS/MS detector was operated at unit resolution in the multiple reaction monitoring mode using the mass transition ion-pairs $\mathrm{m} / \mathrm{z} 284.1 \rightarrow$ $\mathrm{m} / \mathrm{z} 242.0$ for letrozole and $\mathrm{m} / \mathrm{z} 344.3 \rightarrow \mathrm{m} / \mathrm{z} 194.1$ for omeprazole. In order to optimize MS parameters, a standard solution of analyte and internal standard was infused into the mass spectrometer using a syringe pump. Optimized parameters were as follows: Curtain gas, gas 1 and gas 2 (nitrogen) 25, 50 and $55 \mathrm{psi}$, respectively; dwell time $200 \mathrm{~ms}$; source temperature $580{ }^{\circ} \mathrm{C}$; ionspray voltage $-4500 \mathrm{~V}$. Declustering Potential (DP) and Collision Energy (CE) were $-50 \mathrm{~V}$ and $-30 \mathrm{eV}$ for letrozole and $-40 \mathrm{~V}$ and $-19 \mathrm{eV}$ for omeprazole, respectively. The collision gas and interface heater were set to medium and on mode, separately.

\section{Preparation of calibration standards and quality control (QC) samples}

Stock solutions of letrozole $(0.20 \mathrm{mg} / \mathrm{mL})$ were prepared by dissolving $10.00 \mathrm{mg}$ letrozole in a $50-\mathrm{mL}$ volumetric flask and filling the flask to the volume with acetonitrile. These solutions were stored at $4{ }^{\circ} \mathrm{C}$. Plasma standard of letrozole $(1000.00 \mathrm{ng} / \mathrm{mL})$ was prepared freshly by spiking the appropriate stock solutions into the blank plasma. Calibration curve for plasma was prepared using blank plasma spiked at concentrations of $0.30,0.50,1.00,3.00,10.00,30.00$ and $50.00 \mathrm{ng} / \mathrm{mL}$, low, medium and high QC samples for plasma $(0.50,3.00,40.00 \mathrm{ng} / \mathrm{mL})$ were also prepared. The stock solution of internal standard $(0.10 \mathrm{mg} / \mathrm{mL})$ was prepared by dissolving $10.00 \mathrm{mg}$ omeprazole in a $100-\mathrm{mL}$ volumetric flask and diluted to $200.00 \mathrm{ng} / \mathrm{mL}$ working solution with acetonitrile. Care was taken to protect letrozole solutions and QC samples from direct sunlight. In each analytical run, calibration standards, QC samples and unknown bio-samples were extracted together.

\section{Sample preparation}

An aliquot of $100 \mu \mathrm{L}$ plasma was transferred into a $1.5 \mathrm{~mL}$ eppendorf tube, together with $100 \mu \mathrm{L}$ of internal standard working solution. $100 \mu \mathrm{L}$ acetonitrile was added to precipitate plasma proteins, the mixture was vortexed for $30 \mathrm{~s}$ and centrifuged at $12,000 \mathrm{~g}$ for $10 \mathrm{~min}$. The supernatant was transferred into a $200 \mu \mathrm{L}$ autosampler vial and $20 \mu \mathrm{L}$ was injected into LC-MS/MS system.

\section{Assay validation}

The analytical method was validated within the guidelines established by the National Medical Products Administration,
China (NMPA) for bioanalytical method validation. A full validation (calculation curve, selectivity, accuracy, precision, matrix effect, recovery, and stability) was investigated.

Calibration standards and QC samples $(n=6)$ were analyzed on three separate days. Linearity of calibration curves based on peak area ratios of analyte to internal standard was assessed by weighted $\left(1 / x^{2}\right)$ least-squares analysis. Intra- and inter-day precision was calculated by relative standard deviation (RSD) and accuracy was calculated by relative error (RE). The LLOQ was defined as the lowest concentration that could be determined with acceptable signal-to-noise ratio $(\mathrm{S} / \mathrm{N})>10$, inter-day precision $( \pm 20 \%)$ and accuracy $( \pm 20 \%)$. The LOD was determined as the concentration with $\mathrm{S} / \mathrm{N}$ of 3 . The absolute recovery rates of letrozole and omeprazole were evaluated by comparing peak areas of extracted QC samples with those of reference QC solutions reconstituted in blank plasma, respectively. Matrix effects were evaluated by comparing peak areas of QC and internal standard solutions reconstituted in blank plasma extracts with that of the same solutions injected directly into the LC-MS/MS system. Both the absolute recovery rates and matrix effects tests contain three samples in each concentration. Stability of letrozole in plasma was assessed at $-20{ }^{\circ} \mathrm{C}$ for 50 days and three freeze-thaw cycles. After extracting and reconstitution, stability was also investigated in the autosampler at room temperature for $12 \mathrm{~h}$. The samples for stability tests were quantified using freshly prepared calibration curves.

\section{Pharmacokinetic study and incurred sample reanalysis}

The validated method was successfully used in a pharmacokinetic study approved by the NMPA and ethics committee of the Rocket General Hospital PLA (Ethical approval number: 2011003). 24 Chinese healthy volunteers with the age from 20 to 39 years and BMI (body mass index) from 19.2 to $23.9 \mathrm{~kg} / \mathrm{m}^{2}$ received a single dose of $2.5 \mathrm{mg}$ of letrozole tablets $\left(\right.$ Femara $^{\circledR}$, Novartis Pharma Schweiz AG, Switzerland). Blood samples ( $1 \mathrm{~mL}$ each) were collected predose and at $0.25,0.5,0.75,1.0,1.5,2.0,4.0,8.0,12.0,24.0$, 48.0, 96.0, 144.0, 192.0 and $288.0 \mathrm{~h}$ post-dose. Plasma samples were collected from blood samples by centrifugation at $5,000 \mathrm{~g}$ for $5 \mathrm{~min}$, and stored at $-20^{\circ} \mathrm{C}$ prior to analysis.

The pharmacokinetic parameters of letrozole were evaluated by non-compartmental analysis using Phoenix ${ }^{\mathrm{TM}}$ WinNonlin ${ }^{\circledR}$ software version 8.0 and other data were summarized and analyzed using SPSS version 22.0 software.

\section{RESULTS AND DISCUSSION}

\section{Optimization of LC-MS/MS parameters}

Based on our experiences, atmospheric pressure ion (API) was preferred with turbo ESI in negative mode to quantify the letrozole due to its lower levels of background noises. Full-scan negative mode spectra of letrozole and omeprazole contained predominant deprotonated molecules at $\mathrm{m} / \mathrm{z}$ 284.1 and 344.3, respectively. Product ion spectra of $[\mathrm{M}-\mathrm{H}]^{-}$showed fragment ions at $\mathrm{m} / \mathrm{z} 242.0$ and 215.0 for 
letrozole and at $\mathrm{m} / z 194.1$ for omeprazole (Fig. 1). The fragment ions at $\mathrm{m} / z 242.0$ and 194.1 were present in highest abundance and were chosen for multiple reaction monitoring of letrozole and omeprazole, respectively.

The chromatographic conditions, especially the composition of mobile phase, were optimized through several trials to achieve good resolution $(S / N=14.4$, Width $=0.30 \mathrm{~min})$ and symmetric peak shapes of analytes as well as short run time $(2.5 \mathrm{~min})$. It was found that a mixture of acetonitrile and water $(55: 45 \mathrm{v} / \mathrm{v})$ could achieve our purpose and was finally adopted as the mobile phase. With a flow rate of 1.0 $\mathrm{mL} / \mathrm{min}$, the cycle time was $2.5 \mathrm{~min}$ allowing a sample throughput of 500-550 samples per day. Under optimized HPLC conditions, letrozole and omeprazole were detected at retention times of 1.07 and $0.89 \mathrm{~min}$, respectively.

In this study, one-step protein precipitation, which is economical and convenient, was adopted to simplify sample preparation. Comparing with methanol and trifluoroacetic acid, acetonitrile was selected to be the protein precipitant due to excellent precipitation and fewer matrix effects.

\section{Assay validation}

Typical chromatograms are shown in Fig. 2. There was no significant interference from endogenous substances observed at the retention times of the analytes and internal standard. The calibration curves displayed a good linearity characterized, and the ANOVA showed that the linear regression was significant $(P=0.000<0.001)$. The concentration range of the calibration curves was $0.30-50.00 \mathrm{ng} / \mathrm{mL}$ with the LOD of $0.030 \mathrm{ng} / \mathrm{mL}$ by regression coefficients of $\mathrm{r}$ $=0.99$ or higher. From the histogram of the standardized residual, the left and right sides were symmetrical, and the result of the Durbin-Watson independence test was 1.701,
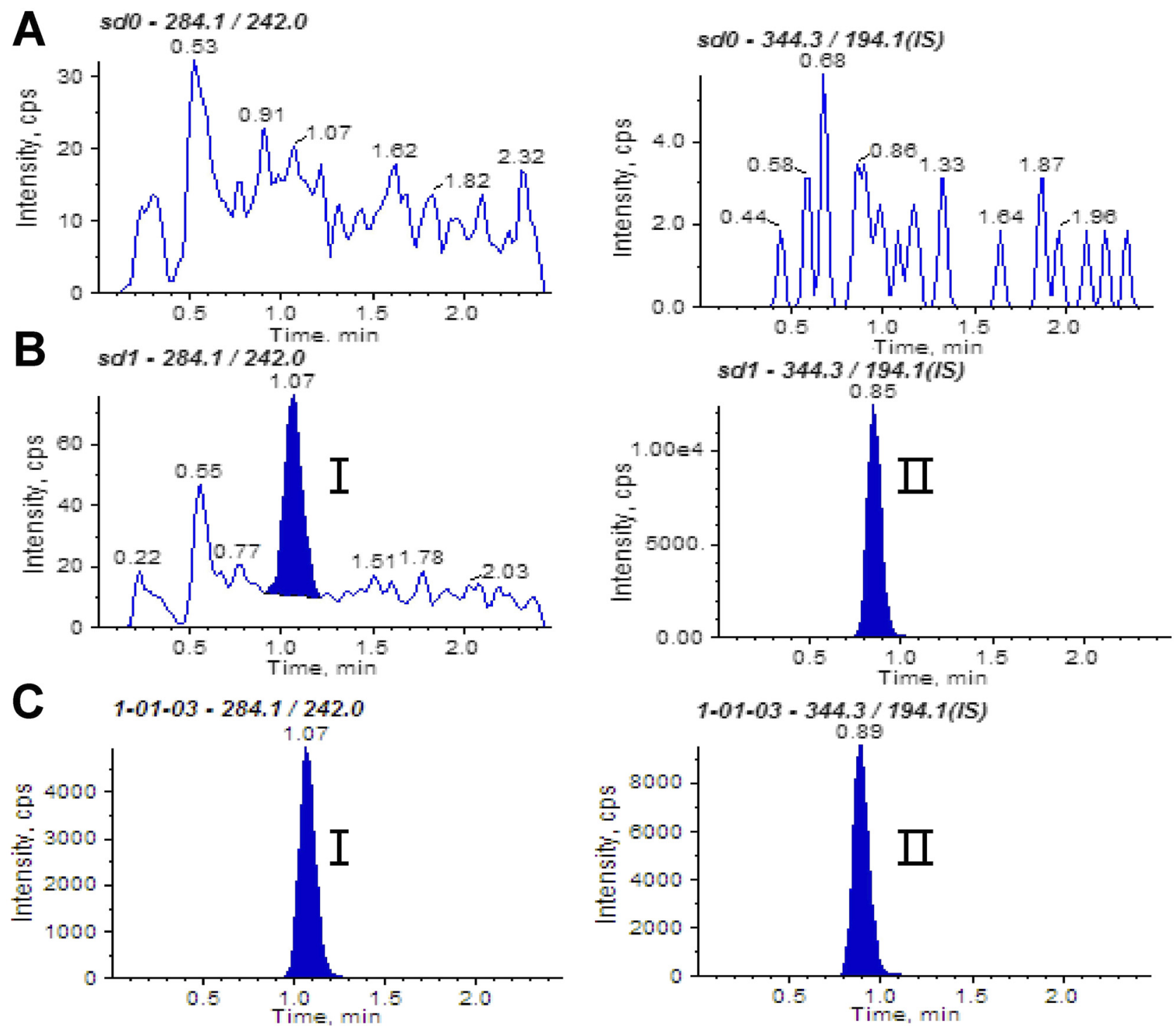

Fig. 2. Representative single reaction monitoring chromatograms of (A) blank plasma, (B) blank plasma spiked with letrozole at the LLOQ $(0.30 \mathrm{ng} / \mathrm{mL})$ and internal standard omeprazole, (C) a plasma sample at $0.5 \mathrm{~h}$ after a single oral administration of $2.5 \mathrm{mg}$ letrozole to healthy volunteers. I, letrozole; II, omeprazole 
which showed the residual conformed to the normal distribution. The typical calibration curve equation was $y=$ $0.0239 x+0.0003$, and the correlation coefficient was 0.9946 . The intra- and inter-day RSD of the QCs were $5.51-8.63 \%$, $2.28-9.95 \%$ and RE was $0.18-1.65 \%$ (Table 1). The absolute recovery rates of letrozole were $89.30 \pm 7.08 \%, 95.44 \pm$ $4.30 \%$ and $98.55 \pm 5.44 \%$ at $0.50,3.00$ and $40.00 \mathrm{ng} / \mathrm{mL}$, respectively. The absolute recovery rate of the internal standard omeprazole was $90.86 \pm 5.28 \%$. In relation to matrix effects, the relative errors based on mean peak areas for both letrozole and internal standard omeprazole were lower than $10 \%$ at all the concentration levels. The results indicated that no co-eluting endogenous substances significantly influenced the ionization of letrozole and internal standard. Letrozole was stable under all the conditions evaluated with RE of $-7.29-7.37 \%$ in Table 2.

\section{Application of method}

The method described above was sensitive enough to quantitate letrozole over a period of $288 \mathrm{~h}$ after giving a single oral dose of $2.5 \mathrm{mg}$ to volunteers. Plasma concentration-time profile for letrozole was displayed in Fig. 3. All the main pharmacokinetic parameters were listed in Table 3.

Table 1. Precision and accuracy for the determination of letrozole in human plasma (6 samples of different concentrations each 3

$$
\text { days) }
$$

\begin{tabular}{lcccc}
\hline $\begin{array}{l}\text { Nominal } \\
\text { conc. } \\
(\mathrm{ng} / \mathrm{mL})\end{array}$ & $\begin{array}{c}\text { Calculated } \\
\text { conc. } \\
(\mathrm{ng} / \mathrm{mL})\end{array}$ & $\begin{array}{c}\text { Intra- } \\
\text { day } \\
\text { RSD }(\%)\end{array}$ & $\begin{array}{c}\text { Inter-day } \\
\text { day } \\
\text { RSD (\%) }\end{array}$ & $\begin{array}{c}\text { RE } \\
(\%)\end{array}$ \\
\hline 0.50 & 0.504 & 7.37 & 8.82 & 0.86 \\
3.00 & 3.05 & 5.51 & 2.28 & 1.65 \\
40.00 & 40.07 & 8.63 & 9.95 & 0.18 \\
\hline
\end{tabular}

The pharmacokinetic results showed that after taking $2.5 \mathrm{mg}$ letrozole, the absorption was fast and the peak time $\left(\mathrm{T}_{\max }=\right.$ $1.98 \pm 1.26 \mathrm{~h}$ ) reached early, the individual difference of the peak concentration $\left(\mathrm{C}_{\max }=26.17 \pm 5.55 \mathrm{ng} / \mathrm{mL}\right)$ was small, but area under curve $\left(\mathrm{AUC}_{0-\mathrm{t}}=1793.65 \pm 808.62 \mathrm{~h} * \mathrm{ng} / \mathrm{mL}\right.$, $\left.\mathrm{AUC}_{0-\infty}=1914.06 \pm 943.78 \mathrm{~h} * \mathrm{ng} / \mathrm{mL}\right)$ showed large individual different. The half-life time $\left(\mathrm{t}_{1 / 2}=54.86 \pm 21.79 \mathrm{~h}\right)$ and average retention time $(\mathrm{MRT}=67.86 \pm 21.19 \mathrm{~h})$ were long and the clearance $(\mathrm{Cl}=1.58 \pm 0.70 \mathrm{~L} / \mathrm{h})$ was slower. The apparent volume of distribution $\left(\mathrm{V}_{\mathrm{z}}=113.25 \pm 54.75\right.$ L) was slightly higher than the volume of total body water of human, which might be distributed in tissues more than blood. In this study a three-compartment model was obtained after single oral administration.

In conclusion, the absorption of letrozole was rapid with small individual difference, the tissue distribution of letrozole was more than that in blood, and the clearance was slow. Letrozole was similar to three-compartment model in

Table 2. Stability data of letrozole during the routine analyses (3 samples of different concentrations each tests)

\begin{tabular}{lrrrr}
\hline & \multicolumn{2}{c}{$\begin{array}{c}\text { Concentration } \\
(\mathrm{ng} / \mathrm{mL})\end{array}$} & $\begin{array}{r}\text { RSD } \\
(\%)\end{array}$ & $\begin{array}{r}\text { RE } \\
(\%)\end{array}$ \\
\cline { 2 - 4 } Storage conditions & 0.50 & 0.51 & 5.79 & 2.53 \\
\cline { 2 - 4 } Freezing for 50 days at & 3.00 & 3.22 & 7.15 & 7.37 \\
$-20{ }^{\circ} \mathrm{C}$ & 40.00 & 41.92 & 9.34 & 4.80 \\
& 0.50 & 0.50 & 6.98 & -0.40 \\
Three freeze-thaw cycles & 3.00 & 3.03 & 2.31 & 1.03 \\
& 40.00 & 41.32 & 8.76 & 3.30 \\
Stability at room & 0.50 & 0.52 & 5.98 & 4.40 \\
temperature for 12 h & 3.00 & 2.84 & 2.67 & -5.22 \\
$\quad$ (after Sample & 40.00 & 37.08 & 7.05 & -7.29 \\
preparation) & & & & \\
\hline
\end{tabular}

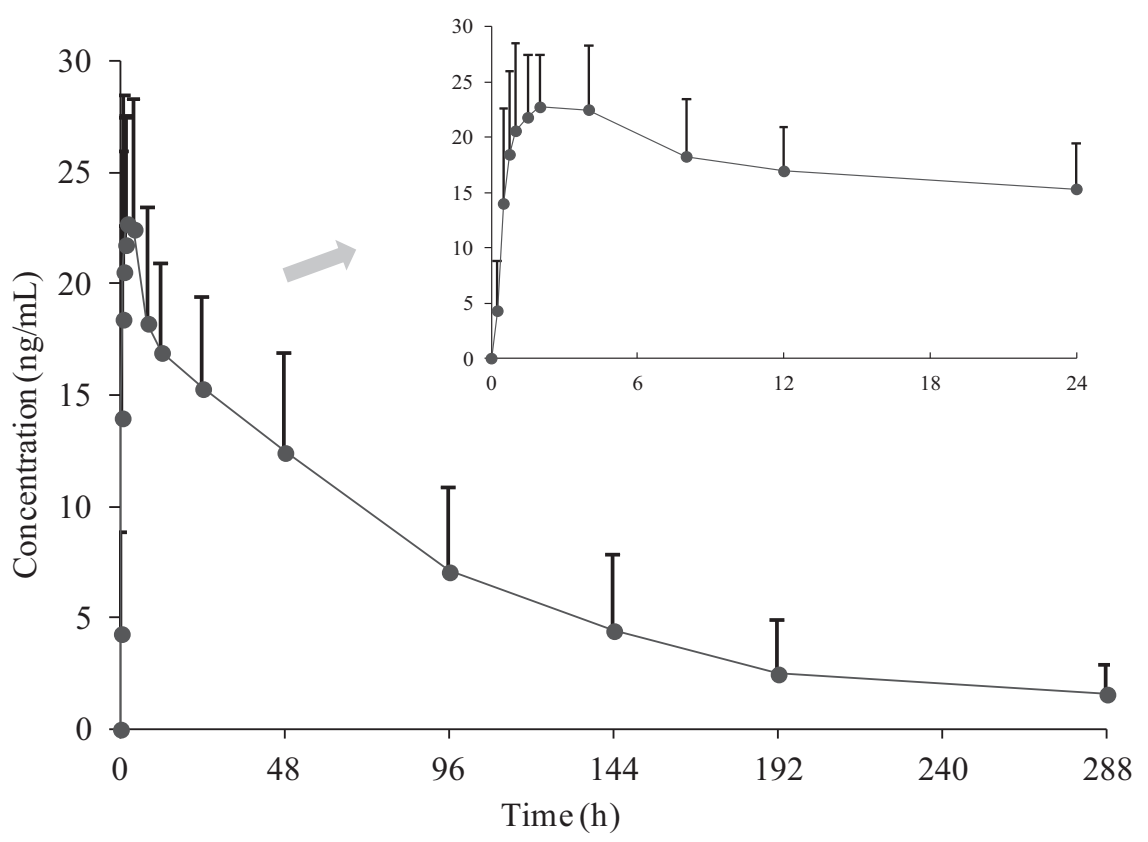

Fig. 3. Plasma concentration-time profile for letrozole with a single dose of $0.25 \mathrm{mg}$. $(n=24)$ 
Table 3. Main pharmacokinetic parameters of letrozole with a single dose of $0.25 \mathrm{mg}$. $(n=24)$

\begin{tabular}{lc}
\hline Parameters & Mean $\pm \mathrm{Sd}$ \\
\hline $\mathrm{t}_{1 / 2}(\mathrm{~h})$ & $54.86 \pm 21.79$ \\
$\mathrm{~T}_{\max }(\mathrm{h})$ & $1.98 \pm 1.26$ \\
$\mathrm{C}_{\max }(\mathrm{ng} / \mathrm{mL})$ & $26.17 \pm 5.55$ \\
$\mathrm{AUC}_{0-\mathrm{t}}\left(\mathrm{h}^{*} \mathrm{ng} / \mathrm{mL}\right)$ & $1793.65 \pm 808.62$ \\
$\mathrm{AUC}_{0-\infty}\left(\mathrm{h}^{*} \mathrm{ng} / \mathrm{mL}\right)$ & $1914.06 \pm 943.78$ \\
$\mathrm{~V}_{\mathrm{z}}(\mathrm{L})$ & $113.25 \pm 54.75$ \\
$\mathrm{Cl}(\mathrm{L} / \mathrm{h})$ & $1.58 \pm 0.70$ \\
MRT $(\mathrm{h})$ & $67.86 \pm 21.19$ \\
\hline
\end{tabular}

vivo. Due to metabolism and excretion, the AUC of letrozole varied greatly among individuals.

\section{CONCLUSIONS}

A LC-MS/MS method for determination of letrozole in human plasma was developed and validated in this study. The method needed one-step protein precipitation procedure only, and the cycle time was $2.5 \mathrm{~min}$ allowing $500-550$ samples per day. The method is linear within $0.30-50.00$ $\mathrm{ng} / \mathrm{mL}$. The precision, sensitivity and selectivity of the method were sufficient to determine the drug in human plasma, and it was successfully used in pharmacokinetic study.

Conflict of interest: The authors declare that they have no conflict of interest associated with this publication, and there has been no significant financial support for this work that could have influenced its outcome.

\section{ACKNOWLEDGMENTS}

This study was supported by National Science and Technology Major Projects for 'Major New Drugs Innovation and Development' (No. 2017ZX09101001).

\section{REFERENCES}

1. Simpson, D.; Curran, M. P.; Perry, C. M. Drugs 2004, 64, 1213-30.

2. Shah, N.; Mohammad, A. S.; Saralkar, P.; Sprowls, S. A., Vickers, S. D.; John, D.; Tallman, R. M.; Lucke-Wold, B. P.; Jarrell, K. E.; Pinti, M.; Nolan, R. L.; Lockman, P. R. Pharmacol. Res. 2018, $132,47-68$.

3. Geisler, J.; Helle, H.; Ekse, D.; Duong, N. K.; Evans, D. B.; Nordbø, Y.; Aas, T.; Lønning, P. E. Clin. Cancer Res. 2008 14, 6330-5.

4. Geisler, J.; Haynes, B.; Anker, G.; Dowsett, M.; Lønning, P. E. J. Clin. Oncol. 2002, 20, 751-7.

5. Sioufi, A.; Sandrenan, N.; Godbillon, J.; Trunet, P.; Czendlik, C.; Howald, H.; Pfister, C.; Ezzet, F. Biopharm. Drug Dispos. 1997, 18, 489-97.

6. Filipe, A.; Almeida, S.; Spínola, A. C.; Trabelsi, F.; Ortuño, J. Arzneimittelforschung. 2008, 58, 419-22.

7. Tanii, H.; Shitara, Y.; Horie, T. Eur. J. Clin. Pharmacol. 2011, 67, 1017-25.

8. Al-Shehri, M.; Hefnawy, M.; Abuelizz, H.; Alzamil, A. Acta Chromatogr. 2020, 32, 170-8.

9. Dange, Y.; Bhinge, S.; Salunkhe, V. Toxicol Mech. Methods. 2018, 28, 187-94.

10. Rodríguez, J.; Castañeda, G.; Muñoz, L. J. Chromatogr. B, 2013, 913-914, 12-8.

11. Flores, J.; Salcedo, A.; Fernández, L. Anal. Chem. Insight. 2008, 3, 91-101.

12. Flores, J.; Salcedo, A.; Llerena, M.; Fernández, L. J. Chromatogr. A, 2008, 1185, 281-90.

13. Shao, R.; Yu, L. Y.; Lou, H. G.; Ruan, Z. R.; Jiang, B.; Chen, J. L. Biomed. Chromatogr. 2016, 30, 632-7.

14. Beer, B.; Schubert, B.; Oberguggenberger, A.; Meraner, V.; Hubalek, M.; Oberacher, H. Anal. Bioanal. Chem. 2010, 398, 1791-800.

15. Precht, J.; Ganchev, B.; Heinkele, G.; Brauch, H.; Schwab, M.; Mürdter, T. Anal. Bioanal. Chem. 2012, 403, 301-8.

16. Vanol, P. G.; Singhal, P.; Shah, P. A.; Shah, J. V.; Shrivastav, P. S.; Sanyal, M. J. Pharm. Anal., 2016, 6, 276-81. 